Annuaire du Collège de France 2017-2018

\title{
Photonique quantique / Quantum photonics
}

Institut de physique

\section{Alexei Ourjoumtsev}

\section{CpenEdition}

\section{Journals}

Édition électronique

URL : https://journals.openedition.org/annuaire-cdf/16212

DOI : $10.4000 /$ annuaire-cdf. 16212

ISBN : 978-2-7226-0572-5

ISSN : 2109-9227

Éditeur

Collège de France

\section{Édition imprimée}

Date de publication : 30 décembre 2020

Pagination : 678

ISBN : 978-2-7226-0516-9

ISSN : 0069-5580

Référence électronique

Alexei Ourjoumtsev, "Photonique quantique / Quantum photonics ", L'annuaire du Collège de France [En ligne], 118 | 2020, mis en ligne le 01 avril 2021, consulté le 22 août 2022. URL : http://

journals.openedition.org/annuaire-cdf/16212 ; DOI : https://doi.org/10.4000/annuaire-cdf.16212 
ZHu Z., FAuqué B., BehNiA K. et FusEYA Y., « Magnetoresistance and valley degree of freedom in bulk bismuth », Journal of Physics: Condensed Matter, vol. 30, $\mathrm{n}^{\mathrm{O}}$ 31, 2018, 313001, DOI : 10.1088/1361-648X/aaced7 [arXiv: 1801.07098].

Collignon C., Lin X., Rischau C.W., Fauqué B. et Behnia K., « Metallicity and superconductivity in doped strontium titanate », Annual Review of Condensed Matter Physics, vol. $10, \mathrm{n}^{\mathrm{o}}$ 1, 2019, p. 25-44, DOI : 10.1146/annurev-conmatphys-031218-013144 [arXiv: 1804.07067].

\section{RECHERCHES SUR LA PHYSIQUE MÉSOSCOPIQUE À PARTIR DE GRAPHĖNE ET DE JONCTIONS JOSEPHSON / JOSEPHSON JUNCTION SPECTROSCOPY OF MESOSCOPIC SYSTEMS}

Responsable : Çağlar GiRiT

\section{RECHERCHE}

Page web : https://www.college-de-france.fr/site/young-team-incubator/ Presentation_2.htm.

\section{PHOTONIQUE QUANTIQUE / QUANTUM PHOTONICS}

Responsable : Alexei OURJOUMTSEV

\section{RECHERCHE}

Page web : https://www.college-de-france.fr/site/young-team-incubator/ Presentation_3.htm.

\section{PHYSIQUE QUANTIQUE}

Responsable : Jean-Michel RAIMOND

\section{RECHERCHE}

Page web : https://www.college-de-france.fr/site/physique-quantique/Presentation.htm.

Notre activité s'est orientée en 2017-2018 vers trois directions principales : jeux quantiques dans les multiplicités de Rydberg; électrodynamique quantique en cavité ; simulation quantique avec les atomes de Rydberg. 